Check for updates

Cite this: Phys. Chem. Chem. Phys., 2020, 22, 5033

Received 27th November 2019 Accepted 23rd December 2019 DOI: $10.1039 / c 9 c p 06386 b$

rsc.li/pccp

\section{A role for low concentration reaction intermediates in the signal amplification by reversible exchange process revealed by theory and experiment $\dagger$}

\author{
Marianna Fekete, (D) a Soumya S. Roy (D) ab and Simon B. Duckett (D) *a \\ A route to monitor the involvement of less abundant species during the catalytic transfer of \\ hyperpolarisation from parahydrogen into a substrate is detailed. It involves probing how the degree of \\ hyperpolarisation transfer catalysis is affected by the magnetic field experienced by the catalyst during \\ this process as a function of temperature. The resulting data allow the ready differentiation of the roles \\ played by hard to detect and highly reactive complexes, such as $\left[\operatorname{lr}(\mathrm{H})_{2}(\mathrm{NHC})(\text { substrate })_{2}(\right.$ methanol) $] \mathrm{Cl}$, \\ from dominant species such as $\left.\left[\operatorname{lr}(\mathrm{H})_{2}(\mathrm{NHC}) \text { (substrate) }\right)_{3}\right] \mathrm{Cl}$. The difference in behaviour results from \\ changes in the interligand spin-spin coupling network within the active SABRE catalysts.
}

Nuclear magnetic resonance (NMR) spectroscopy is a relatively insensitive analytic technique that requires large amounts of sample when compared to other routine characterisation methods. Its low sensitivity can be readily improved by premagnetising hyperpolarisation techniques. ${ }^{1-3}$ One of these hyperpolarisation approaches is termed SABRE (Signal Amplification By Reversible Exchange). ${ }^{4}$ It employs parahydrogen $\left(p-\mathrm{H}_{2}\right)^{5,6}$ as the source of hyperpolarisation and is particularly popular because of its low-cost and rapidity.

Long-lived $p-\mathrm{H}_{2}$ is associated with a nuclear singlet state which can be easily prepared, and is invisible to NMR spectroscopy. ${ }^{8}$ In SABRE, the magnetic symmetry of this state is broken by reversibly converting its two hydrogen atoms into hydride ligands through binding to a metal complex. When this complex also reversibly binds the substrate that is set to be hyperpolarised, polarisation flows catalytically between their nuclear spins through the transient $J$-coupling network. ${ }^{4,9,10}$ Consequently, the efficiency of SABRE is highly dependent on the lifetime of the complex which must match the propagating resonance condition leading to transfer. ${ }^{11-13}$ It also relies on setting the magnetic field the sample experiences during the transfer step to a value of around $60 \mathrm{G}$ when ${ }^{1} \mathrm{H}$ nuclei are targeted, but much lower $\mathrm{mG}$ fields are needed for ${ }^{15} \mathrm{~N}$ and ${ }^{13} \mathrm{C}$ nuclei. ${ }^{14-16}$ Given these constraints, the level of NMR signal enhancement can be improved

\footnotetext{
${ }^{a}$ Centre for Hyperpolarisation in Magnetic Resonance, Department of Chemistry, University of York, Heslington, York, YO10 5NY, UK.

E-mail: simon.duckett@york.ac.uk

${ }^{b}$ Department of Inorganic and Physical Chemistry, Indian Institute of Science, Bangalore 560012, India

$\dagger$ Electronic supplementary information (ESI) available. See DOI: 10.1039/ c9ср06386b
}

through catalyst design and by sharing the hyperpolarisation source $p-\mathrm{H}_{2}$ with fewer receptor spins in conjunction with deuterium labelling which also reduces relaxation effects. ${ }^{17,18,19}$ In fact, relaxation is one of the major obstacles to hyperpolarisation research as it is associated with signal destruction and minimising its effect on this use-once NMR detection method is critical. ${ }^{20}$ Specially created longer-lived states have been harnessed to alleviate these relaxation issues, often in conjunction with rationally designed substrates and catalysts. ${ }^{14,21-26}$ The role of the catalyst in SABRE has recently been reviewed. ${ }^{27}$

Because of the catalytic nature of SABRE, hard to detect reaction intermediates might be expected to play a role in this process and we show here that their effect is currently underestimated. In fact, understanding the role played by minor species in catalysis is always a challenge, and yet it reflects a key feature of optimising reactivity. ${ }^{28,29} \mathrm{We}$ achieve insight into SABRE by correlating theoretical predictions s $^{10,15,16,30,31}$ with experimental data using the substrate 4,6 dideuteronicotinate $\left(\mathbf{d}_{2}-\mathbf{N A}\right)$ in the first instance. This builds from the fact that the $\mathbf{d}_{2}$-NA reflects a simple 2-spin system whose proton relaxation times are sufficiently long that they aid in the accurate monitoring of the resulting spin systems.

\section{Theoretical SABRE predictions}

Our NMR theory studies using a reported approach ${ }^{10}$ reveal that the SABRE catalyst $\left[\operatorname{Ir}(\mathrm{H})_{2}\left(\mathrm{Cl}-\mathrm{IPhMe}{ }_{2}\right)\left(\mathbf{d}_{2}-\mathbf{N A}\right)_{2}\left(\mathrm{CH}_{3} \mathrm{CN}\right)\right] \mathrm{Cl}$ (Type A of Scheme 1) with two chemically inequivalent hydride ligands will produce a polarisation transfer field (PTF) profile with either one or two maxima according to the size of the 

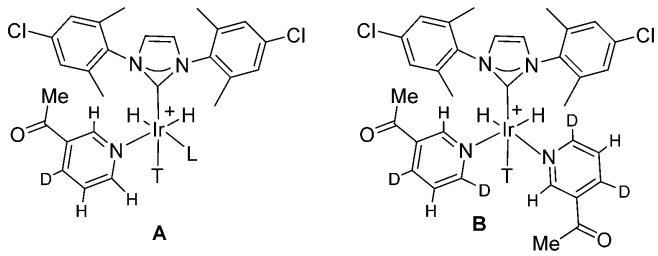

Scheme 1 Structures of catalysts involved in SABRE. $\mathrm{L}=\mathrm{NCMe}, \mathrm{Cl}-$ or $\mathrm{MeOH} . \mathrm{T}=$ trans ligand needed to maintain 18 electron count.

interproton coupling in the $\mathbf{d}_{\mathbf{2}}$-NA substrate. One or two maxima also result for situation $\mathbf{B}$, according to the size of the interproton coupling, when species such as $\left[\operatorname{Ir}(\mathrm{H})_{2}\left(\mathrm{Cl}-\mathrm{IPhMe}{ }_{2}\right)\left(\mathbf{d}_{2}-\mathbf{N A}\right)_{3}\right] \mathrm{Cl}$, that possess chemically equivalent but magnetically distinct hydrides are involved, as described in the ESI. $\dagger^{3,4}$

In order to obtain this perspective, our calculations treat the $\mathbf{d}_{\mathbf{2}}$-NA derived complexes as a four spin system and neglect any role for the axial ligands of Scheme 1. Adiabatic propagation into the measurement field is also assumed. A graphical perspective of the effect this coupling plays on the resulting SABRE transfer process is shown in Fig. 1 for a four spin system of type A involving inequivalent hydride ligands. The PTF profile spits from a single peak centred at around $60 \mathrm{G}$ to two peaks as in Fig. 1f, as the interproton $\mathrm{H} 2-\mathrm{H} 5$ spin-spin coupling increases from 0.7 to $1.7 \mathrm{~Hz}$. We have also probed the effects $J_{\mathrm{HH}}$, the hydride-hydride coupling, and the trans hydride- $\mathrm{H} 2$ proton coupling of these complexes play on the resulting PTF profile. The former situation was found to simply move the PTF peak centres while the latter had minimal effect on the PTF profile shape but did change intensity. This suggests that we can readily distinguish contributions from type $\mathbf{A}$ and type $\mathbf{B}$ spin systems if binding creates a difference in the interproton spin-spin couplings in their bound ligands.

\section{Experimental SABRE results}

The linked experimental studies were completed in conjunction with an automated flow apparatus that has been described previously. ${ }^{32,33}$ It was modified for this work to enable variable temperature measurement (see ESI $\dagger$ ). While the temperature of the solution undergoing catalysis is varied here, all of the measurements take place at $298 \mathrm{~K}$ after the sample is transferred from the reaction cell into the observation flow-probe which was located in a $9.4 \mathrm{~T}$ field.

These studies into the role that the magnetic field experienced by the sample (the polarisation transfer field or PTF) at the point of catalysis plays on the resulting NMR signal intensity gains started by taking the precatalyst $\left[\mathrm{IrCl}(\mathrm{COD})\left(\mathrm{Cl}-\mathrm{IPhMe}_{2}\right)\right]$ (where Cl-IPhMe $\mathrm{I}_{2}=$ 1,3-bis(4-chloro-2,6-dimethylphenyl)imidazole-2-ylidine) ${ }^{34}$ which is good for nicotinamide and reacting it with $\mathbf{d}_{2}$-NA which binds to iridium through its nitrogen centre in $\mathrm{d}_{4}$-methanol solution under an atmosphere of $\mathrm{H}_{2}$. NMR methods were used to show that it forms low concentrations of $\left[\operatorname{Ir}(\mathrm{H})_{2}\left(\mathrm{Cl}-\mathrm{IPhMe}_{2}\right)\left(\mathbf{d}_{2}-\mathbf{N A}\right)_{2}{ }^{-}\right.$ (methanol)]Cl and $\operatorname{Ir}(\mathrm{Cl})(\mathrm{H})_{2}\left(\mathrm{Cl}-\mathrm{IPhMe}_{2}\right)\left(\mathbf{d}_{\mathbf{2}}-\mathbf{N A}\right)_{2}$ alongside the more usual well-established type $\mathbf{B}$ form of such catalysts, $\left[\operatorname{Ir}(\mathrm{H})_{2}(\mathrm{Cl}-\mathrm{IPhMe})_{2}\left(\mathbf{d}_{\mathbf{2}}-\mathbf{N A}\right)_{3}\right] \mathrm{Cl}$, in solution. The corresponding
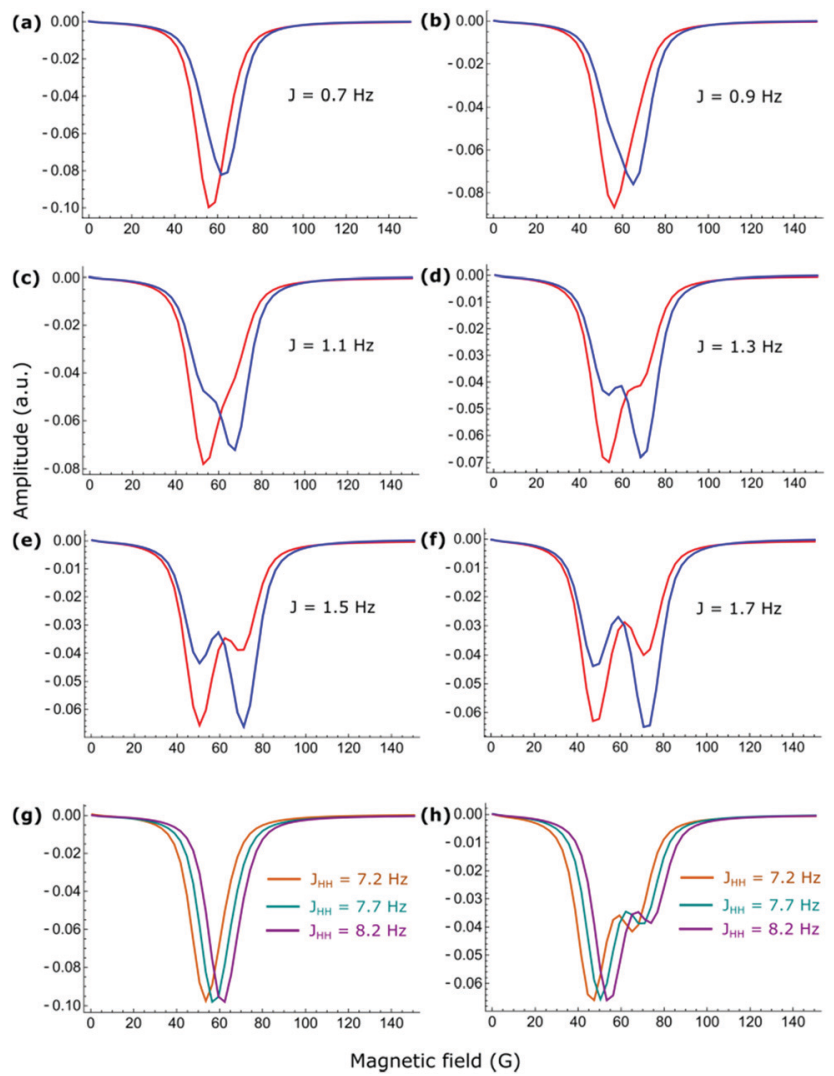

Fig. 1 (a-f) Theoretically predicted ${ }^{1} H$ NMR SABRE signal gain profiles as a function of polarisation transfer field (PTF) for the substrate $d_{2}-4,6$ nicotinamide. The six plots detailing the ortho (red, $\mathrm{H} 2$ ) and meta (blue, H5) proton responses were produced by the action of a type $\mathbf{A}$ catalyst of Scheme 1 and involve the use of the listed interproton couplings between $\mathrm{H} 2$ and $\mathrm{H} 5$. The hydride-hydride coupling was set to $7.7 \mathrm{~Hz}$, and the trans-hydride- $\mathrm{H} 2$ coupling $0.7 \mathrm{~Hz}$. Plot (g) illustrate the effect the hydride-hydride couplings (indicated) on the PTF profile for the ortho proton $(\mathrm{H} 2)$ resonance when the hydride $-\mathrm{H} 2$ coupling is fixed at $0.7 \mathrm{~Hz}$ and the $\mathrm{H} 2-\mathrm{H} 5$ coupling fixed at $0.7 \mathrm{~Hz}$. Plot ( $h$ ) is the same as (g) except now the $\mathrm{H} 2-\mathrm{H} 5$ coupling is $1.5 \mathrm{~Hz}$. See Fig. S10 and S11, ESI† far analogous plots for type B systems.

${ }^{1} \mathrm{H}$ NMR measurements at $263 \mathrm{~K}$ revealed hydride ligand signals at $\delta-22.89$ for the tris-substituted complex, and at $\delta$ -21.50 and -27.98 for the methanol adduct, and at $\delta-23.84$ and -25.19 for the chloride derivative; these structures reflect situation A. ${ }^{35,36}$

These three species exist in this solution in a ratio of $7.9: 1.1: 1$ respectively and could all contribute to the SABRE process wherein $\mathbf{d}_{\mathbf{2}}$-NA becomes sensitised for NMR detection. At $296 \mathrm{~K}$, the PTF profile seen for $\mathbf{d}_{\mathbf{2}}$-NA under SABRE is shown in Fig. 2. These plots reflect single broad peaks for both the ortho- $2 \mathrm{H}$ and meta-4H signals. However, at $303 \mathrm{~K}$, the meta-4H proton signal intensity versus PTF profile changes (red) and two clearly distinct maxima begin to resolve. Upon changing the precatalyst to $\left[\operatorname{IrCl}(\mathrm{COD})\left(\mathrm{d}_{16}-\mathrm{Cl}-\mathrm{IPhMe}_{2}\right)\right]$ and completing a similar series of measurements, both the $303 \mathrm{~K}$ ortho and meta proton PTF profiles were found to exhibit clearer maxima (Fig. 2b) which means we are more confident in this observation.

In order to obtain an experimental rational for this behaviour, we cooled the resulting NMR solutions to $263 \mathrm{~K}$ where ligand 


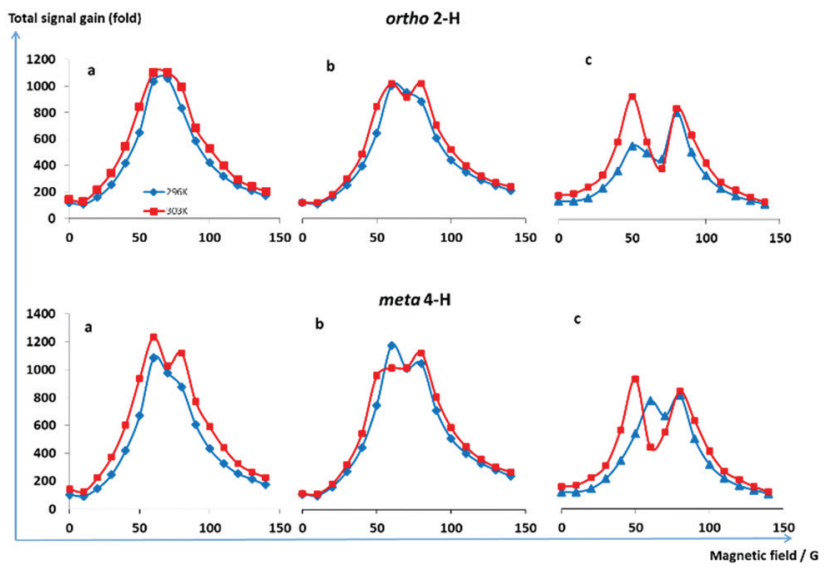

Fig. 2 (a) The SABRE intensity ${ }^{1} \mathrm{H} N M R$ signal gains for $\mathbf{d}_{\mathbf{2}}-\mathrm{NA}\left(\mathrm{d}_{2}-4,6\right.$ nicotinamide, upper ortho proton and lower meta) at the indicated temperature at a function of PTF for precatalyst [IrCl(COD)(Cl-IPhMe $)$ ] $(5.2 \mathrm{mM})$ with seven substrate equivalents relative to iridium in $\mathrm{d}_{4}$-methanol solution and 3 bar $p-\mathrm{H}_{2}$. (b) as (a) but with precatalyst $\left[\mathrm{IrCl}(\mathrm{COD})\left(\mathrm{d}_{16}-\mathrm{Cl}-\right.\right.$ IPhMe 2 )]. (c) as for (a) but in the presence of additional $\mathrm{CH}_{3} \mathrm{CN}$.

exchange is slowed. A series of selective $1 \mathrm{D} \mathrm{COSY}^{37}$ measurements were then undertaken to probe the build-up of the crosspeak associated with magnetisation transfer due to the five bond ${ }^{1} \mathrm{H}-{ }^{1} \mathrm{H}$ coupling that exist between $\mathrm{H} 2$ and $\mathrm{H} 5$ in the bound $\mathrm{d}_{2}$-4,6-nicotinamide ligand that lies trans to hydride, in both $\left[\operatorname{Ir}(\mathrm{H})_{2}(\mathrm{Cl}-\mathrm{IPhMe})_{2}\left(\mathbf{d}_{2}-\mathbf{N A}\right)_{3}\right] \mathrm{Cl}$ and $\left[\operatorname{Ir}(\mathrm{H})_{2}\left(\mathrm{Cl}-\mathrm{IPhMe}_{2}\right)\left(\mathbf{d}_{\mathbf{2}}-\mathbf{N A}\right)_{2^{-}}\right.$ $\left.\left(\mathrm{NCCH}_{3}\right)\right] \mathrm{Cl}$. The associated maxima proved to be indicative of 1.17 and $1.38 \mathrm{~Hz}$ couplings respectively which would be predicted to yield PTF field plots tending towards two maxima respectively as detailed in Fig. 1 and 2c. These measurements were completed at $265 \mathrm{~K}$ in order to suppress ligand exchange during data collection. We also examined a separate dichloromethane- $\mathrm{d}_{2}$ solution of $\operatorname{Ir}(\mathrm{Cl})(\mathrm{H})_{2}\left(\mathrm{~d}_{22}\right.$-IMes $)\left(\mathbf{d}_{2}-\mathbf{N A}\right)_{2}$ in order to measure the corresponding $2 \mathrm{H}-5 \mathrm{H}$ coupling. However, ligand rotation is inhibited at the low temperatures needed for this measurement and consequently the resonances proved too broad to make such an assignment possible. The methanol adducts are also present at such low abundance that similar measurements on them proved to be impossible, but given the similarity in hydride chemical shifts of these species and the common involvement of electronegative ligation sites, it would seem reasonable to assume similar behaviour. Reported kinetic studies on ligand loss in type A and B complexes yield different rate constants which would be consistent with different Sigma bonding frameworks and hence differences in the associated couplings. ${ }^{18}$ As the situation with $\left[\operatorname{Ir}(\mathrm{H})_{2}\left(\mathrm{Cl}-\mathrm{IPhMe}_{2}\right)\left(\mathbf{d}_{2}-\mathbf{N A}\right)_{2}\left(\mathrm{NCCH}_{3}\right)\right] \mathrm{Cl}$, or a type A catalyst will yield two maxima, it would seem sensible to suggest based on these data that its contribution grows with increase in temperature.

We note that it is difficult to see the PTF behaviour in these plots as the peak profiles of Fig. 2 are quite broad. Under these conditions, one way to improve the visualisation of this effect turns out to plot the sum of the $\mathrm{H} 2$ and $\mathrm{H} 5$ peak intensities as shown in Fig. 3a. However, the related 2-proton substrate methyl-4,6$\mathrm{d}_{2}$-nicotinate $\left(\mathbf{d}_{\mathbf{2}}-\mathbf{M N}\right)$, which has also been extensively examined by SABRE, proves to yield more visible effects. This reagent reacts to forms analogous $\left[\operatorname{Ir}(\mathrm{H})_{2}\left(\mathrm{~d}_{22}\right.\right.$-IMes $)\left(\mathbf{d}_{2}-\mathbf{M N}\right)_{2}$ (methanol) $] \mathrm{Cl}$ and $\left[\operatorname{Ir}(\mathrm{H})_{2}\left(\mathbf{d}_{22}\right.\right.$-IMes $\left.)\left(\mathbf{d}_{2}-\mathbf{M N}\right)_{3}\right]$ Cl complexes in solution.

The corresponding SABRE $\mathrm{H} 2$ and $\mathrm{H} 5$ resonances ${ }^{1} \mathrm{H}$ NMR signals PTF results are shown in Fig. $3 \mathrm{~b}$ and $\mathrm{c}$ for $\mathbf{d}_{\mathbf{2}}-\mathbf{M N}$. In this case, the measurements were recorded over the temperature range $283 \mathrm{~K}$ to $303 \mathrm{~K}$. It is clear from these data that there are two maxima whose separation increases with temperature. This would logically reflect be a growing contribution from the type A catalyst $\left[\operatorname{Ir}(\mathrm{H})_{2}\left(\mathrm{~d}_{22}\right.\right.$-IMes $)\left(\mathbf{d}_{2}-\mathbf{M N}\right)_{2}($ methanol $\left.)\right] \mathrm{Cl}$ if its $\mathrm{H} 2$ to H5 coupling was large. As the former situation would yield two maxima it seems sensible to suggest its contribution grows with temperature.

It is worthy of note that when the proton resonances of the more complex substrate NA are examined under SABRE using the same automated device at $296 \mathrm{~K}$ the summed ${ }^{1} \mathrm{H}$ NMR signal intensity profile shows a simple maximum centred at $70 \mathrm{G}^{3,25}$ However, upon warming to $303 \mathrm{~K}$, the observed SABRE field profile broadens thereby suggesting greater contributions now arise from $\left[\operatorname{Ir}(\mathrm{H})_{2}\left(\mathrm{Cl}-\mathrm{IPhMe}_{2}\right)(\mathrm{NA})_{2}(\right.$ methanol $\left.)\right] \mathrm{Cl}$ and $\operatorname{Ir}(\mathrm{H})_{2}\left(\mathrm{Cl}-\mathrm{IPhMe}_{2}\right)(\mathrm{NA})_{2}(\mathrm{Cl})$ type species.

The related substrate methyl-4,6- $\mathbf{d}_{2}$-nicotinate $\left(\mathbf{d}_{2}-\mathbf{M N}\right)$ has also been extensively examined by SABRE. This reagent forms $\left[\operatorname{Ir}(\mathrm{H})_{2} \operatorname{IMes}(\mathrm{MN})_{2}(\right.$ methanol $\left.)\right] \mathrm{Cl}$ and $\left[\operatorname{Ir}(\mathrm{H})_{2} \operatorname{IMes}(\mathrm{MN})_{3}\right] \mathrm{Cl}$ in a $1: 4$ ratio when the initial ligand excess is 7 relative to iridium. The corresponding SABRE results are shown Fig. 3 for the
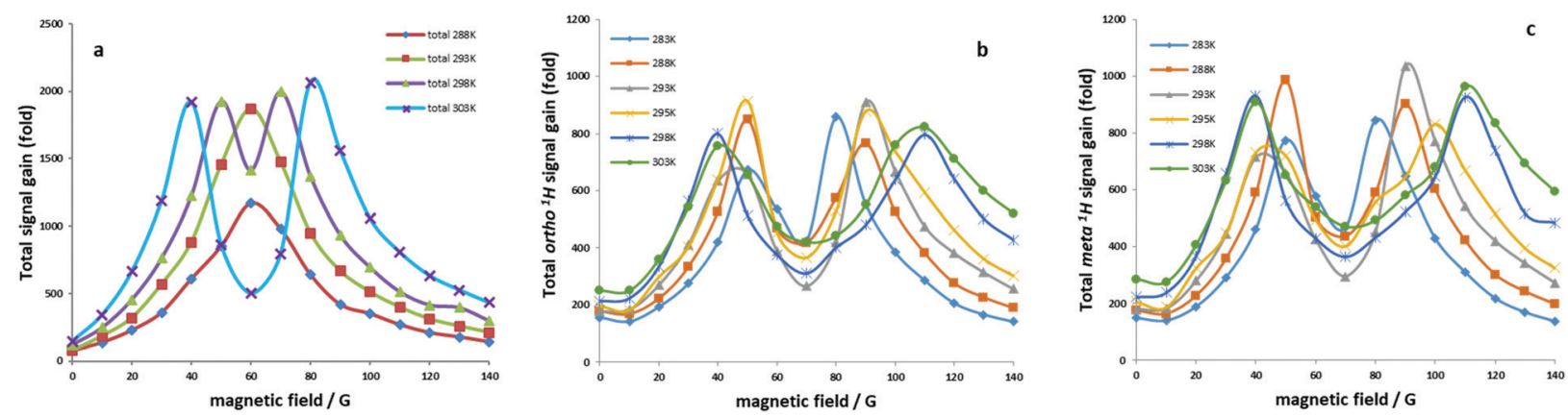

Fig. 3 (a) Summed SABRE intensity ${ }^{1} \mathrm{H}$ NMR signal gains for $\mathbf{d}_{2}-4,6$-nicotinate $\left(\mathbf{d}_{\mathbf{2}}-\mathbf{M N}\right)$ at the indicated temperatures as a function of PTF for precatalyst [IrCl(COD) $\left.\left(\mathrm{d}_{16}-\mathrm{Cl}-\mathrm{IPhMe}\right)\right](5.2 \mathrm{mM})$ with seven substrate equivalents in $\mathrm{d}_{4}$-methanol solution using 3 bar of $p-\mathrm{H}_{2}$. (b) SABRE ${ }^{1} \mathrm{H}$ ortho proton NMR signal gain versus PTF for methyl-4,6- $\mathrm{d}_{2}$-nicotinate through the action of $\left[\operatorname{IrCl}(\mathrm{COD})\left(\mathrm{d}_{22}-\mathrm{IMes}\right)\right]$. (c) as for (b) but the meta proton signal. 
related precatalysts $\left[\operatorname{IrCl}(\mathrm{COD})\left(\mathrm{d}_{16}-\mathrm{Cl}-\mathrm{IPhMe}_{2}\right)\right]$ and $[\mathrm{IrCl}(\mathrm{COD})-$ $\left(\mathrm{d}_{22}\right.$-IMes)] which due to their deuteration again yield better resolved PTF peak profiles than their protio catalyst counterparts. In this case, the measurements were recorded over the temperature range $288 \mathrm{~K}$ to $303 \mathrm{~K}$ to more precisely encode this change with temperature.

It is clear from these data that the peak centres associated with the two maxima separate as what must be the contribution from the $\mathbf{B}$ type catalyst $\left[\operatorname{Ir}(\mathrm{H})_{2}\left(\mathrm{~d}_{22}-\mathrm{IMes}\right)\left(\mathbf{d}_{2}-\mathbf{M N}\right)_{3}\right] \mathrm{Cl}$ reduces. Furthermore, the overall level of signal gain initially increases before falling as the reaction kinetics must match the transfer condition more closely before ligand dissociation becomes too fast. These data therefore confirm that the contribution from $\left[\operatorname{Ir}(\mathrm{H})_{2}-\right.$ $\left(\mathrm{d}_{22}\right.$-IMes) $\left(\mathbf{d}_{2}-\mathbf{M N}\right)_{2}($ methanol $\left.)\right] \mathrm{Cl}$ or $\left[\mathrm{Ir}(\mathrm{H})_{2}\left(\mathrm{~d}_{22}\right.\right.$-IMes $\left.)\left(\mathbf{d}_{2}-\mathbf{M N}\right)_{2}\right] \mathrm{Cl}$ to the SABRE outcome is highly significant even at $295 \mathrm{~K}$.

In order to probe this, the $2 \mathrm{H}-5 \mathrm{H}$ couplings in the bound $\mathbf{d}_{2}$-MN ligands that lie trans to hydride in $\left[\operatorname{Ir}(\mathrm{H})_{2}\left(\mathrm{~d}_{22}\right.\right.$-IMes)$\left.\left(\mathbf{d}_{2}-\mathbf{M N}\right)_{2}\left(\mathrm{CH}_{3} \mathrm{CN}\right)\right] \mathrm{Cl}$ and $\left[\operatorname{Ir}(\mathrm{H})_{2}\left(\mathrm{~d}_{22}-\mathrm{IMes}\right)\left(\mathbf{d}_{2}-\mathbf{M N}\right)_{3}\right] \mathrm{Cl}$ were measured at $265 \mathrm{~K}$ by $1 \mathrm{D}$ COSY. They proved to be $1.62 \mathrm{~Hz}$ and $1.17 \mathrm{~Hz}$ respectively. Consequently, we establish not only that there is a variation of this coupling with complex identity, but that in this case greater peak separation should result. Furthermore, we note the overall level of signal gain initially increases before falling. This change reflects the underlying reaction kinetics which must initially match the polarisation transfer condition more closely ${ }^{20}$ before the ligand dissociation step becomes too fast. Hence these data suggest that contributions from either $\left[\operatorname{Ir}\left(\mathrm{H}_{2}\right)_{2}\left(\mathrm{~d}_{22}\right.\right.$-IMes $)\left(\mathbf{d}_{2}-\mathbf{M N}\right)_{2}$ (methanol) $] \mathrm{Cl}$ or $\operatorname{Ir}(\mathrm{H})_{2}\left(\mathrm{~d}_{22}\right.$-IMes $)\left(\mathbf{d}_{2}-\mathbf{M N}\right)_{2} \mathrm{Cl}$ to the SABRE outcome are highly significant even at $295 \mathrm{~K}$.

As a consequence of these results, the original SABRE test agent pyridine (py) was also re-examined. As might be expected, the shape of the resulting experimental PTF profiles change with temperature which suggests species beyond $\left[\operatorname{Ir}(\mathrm{H})_{2}(\mathrm{IMes})(\mathrm{py})_{3}\right] \mathrm{Cl}$ are again involved. In this case, the two flanking peaks are masked in the summed total ${ }^{1} \mathrm{H}$ NMR signal intensity plot, but they readily appear in the meta resonance profile (Fig. 4). Hence, a role for $\mathbf{A}$ and $\mathbf{B}$ type catalysts, with their different coupling topologies, can again be rationalised.

The highest ortho ${ }^{1} \mathrm{H}$ NMR signal enhancement gain per proton of 2406 -fold for py resulted results at $293 \mathrm{~K}$. Here the pyridine loss rate in $\left[\operatorname{Ir}(\mathrm{H})_{2}(\mathrm{IMes})(\mathbf{p y})_{3}\right] \mathrm{Cl}$ is reported to be $7.51 \mathrm{~s}^{-1}$. Increasing this temperature by just 5 degrees decreases this hyperpolarisation level by almost $38 \%$ to 1492 -fold in reflection of the fact the ligand loss rate changes by $43 \%$ to $13.3 \mathrm{~s}^{-1}$. Consequently, while the ligand exchange rates associated with the temperature at which SABRE catalysis takes place are critical, they do not provide the whole explanation. In fact, as shown here, care must be taken to assess the involvement of minor species if any form of rigorous analysis is to be undertaken.

In summary, this article has established how the SABRE hyperpolarisation technique can also be used to probe these chemical systems for the presence of low concentration species involved in catalysis. This is possible because the shape of the signal intensity profiles for hyperpolarised substrate resonances as a function of polarisation transfer field (PTF) are affected by

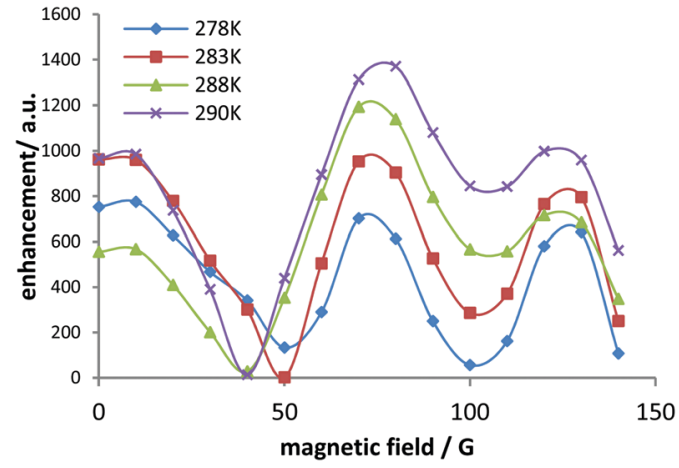

Fig. 4 Series of SABRE ${ }^{1} \mathrm{H}$ NMR versus PTF (G) data for pyridine showing absolute values of the experimental meta proton signal gains achieved for a $5.2 \mathrm{mM}$ concentration of $\left[\mathrm{Ir}(\mathrm{H})_{2}(\mathrm{IMes})(\mathrm{py})_{3}\right] \mathrm{Cl}$ in conjunction with a 4 -fold excess of pyridine.

temperature. In the case of nicotinamide, nicotinate and pyridine the associated experimental behaviour proved to be consistent with roles for two types of polarisation transfer catalyst (A and $\mathbf{B}$ ) whose SABRE outcome differs due to variations in the interproton couplings within the bound ligand set to receive polarisation from the $p-\mathrm{H}_{2}$ derived hydride ligands. Experimentally, the effects of the two types of catalyst combine such that when the PTF profiles are examined as a function of temperature the associated variations in shape enable their involvement to be seen.

In this case, we were fortunate that the type $\mathbf{A}$ and $\mathbf{B}$ species exhibit sufficiently different coupling topologies to enable these effects to be made readily visible. Conformation of this was achieved by studying the effect of acetonitrile which leads to the formation of $\left[\mathrm{Ir}(\mathrm{H})_{2}(\mathrm{NHC})(\text { substrate })_{2}\left(\mathrm{CH}_{3} \mathrm{CN}\right)\right] \mathrm{Cl}$ as the dominant species in solution. Its NMR characterisation was probed alongside that of $\left[\operatorname{Ir}(\mathrm{H})_{2}(\mathrm{NHC})(\text { substrate })_{3}\right] \mathrm{Cl}$ for $\mathbf{d}_{2}-\mathbf{N A}$ and $\mathbf{d}_{2}-\mathbf{M N}$ and the resulting trends in interproton couplings found to the track theoretical predications based on roles for $\left[\operatorname{Ir}(\mathrm{H})_{2}(\mathrm{NHC})\right.$ (substrate $)_{2}($ methanol) $] \mathrm{Cl}$ and $\operatorname{IrCl}(\mathrm{H})_{2}(\mathrm{NHC})(\text { substrate })_{2}$ which are predicted to exhibit similar coupling effects to those of the $\mathrm{CH}_{3} \mathrm{CN}$ adducts. While changes in conformational dynamics with temperature could change the spin-spin couplings in these complexes, we predict these effects would be much more subtle than the changes needed to replicate these results.

Hence the results portrayed here detail a route to probe for reaction intermediates in catalysis based on how they affect the evolution of polarisation under SABRE as a function of temperature. While a range of theoretical studies have been reported that detail how the propagation of spin polarisation during SABRE occurs, it is clear that if theoretical predictions $\mathrm{s}^{20,30,31,38,39}$ are to accurately map onto experimental data ${ }^{40}$ they will need to take into account contributions from a range of species in solution. We expect that these results will be of interest to those seeking to model SABRE and those involved more generally in the study of catalysis.

\section{Conflicts of interest}

Authors declare no conflict of interest. 


\section{Acknowledgements}

We thank Peter Rayner for providing some of the reactants used in this study and the Wellcome Trust for funding (grant numbers 092506 and 098335).

\section{Notes and references}

1 J. H. Ardenkjaer-Larsen, B. Fridlund, A. Gram, G. Hansson, L. Hansson, M. H. Lerche, R. Servin, M. Thaning and K. Golman, Proc. Natl. Acad. Sci. U. S. A., 2003, 100, 10158-10163.

2 B. M. Goodson, J. Magn. Reson., 2002, 155, 157-216.

3 R. A. Green, R. W. Adams, S. B. Duckett, R. E. Mewis, D. C. Williamson and G. G. R. Green, Prog. Nucl. Magn. Reson. Spectrosc., 2012, 67, 1-48.

4 R. W. Adams, J. A. Aguilar, K. D. Atkinson, M. J. Cowley, P. I. P. Elliott, S. B. Duckett, G. G. R. Green, I. G. Khazal, J. López-Serrano and D. C. Williamson, Science, 2009, 323, 1708-1711.

5 J. B. Hovener, A. N. Pravdivtsev, B. Kidd, C. R. Bowers, S. Gloggler, K. V. Kovtunov, M. Plaumann, R. Katz-Brull, K. Buckenmaier, A. Jerschow, F. Reineri, T. Theis, R. V. Shchepin, S. Wagner, P. Bhattacharya, N. M. Zacharias and E. Y. Chekmenev, Angew. Chem., Int. Ed., 2018, 57, 11140-11162.

6 C. R. Bowers and D. P. Weitekamp, J. Am. Chem. Soc., 1987, 109, 5541-5542.

7 P. J. Rayner and S. B. Duckett, Angew. Chem., Int. Ed., 2018, 57, 6742-6753.

8 C. R. Bowers and D. P. Weitekamp, Phys. Rev. Lett., 1986, 57, 2645-2648.

9 K. D. Atkinson, M. J. Cowley, P. I. P. Elliott, S. B. Duckett, G. G. R. Green, J. López-Serrano and A. C. Whitwood, J. Am. Chem. Soc., 2009, 131, 13362-13368.

10 R. W. Adams, S. B. Duckett, R. A. Green, D. C. Williamson and G. G. R. Green, J. Chem. Phys., 2009, 131, 194505.

11 M. J. Cowley, R. W. Adams, K. D. Atkinson, M. C. R. Cockett, S. B. Duckett, G. G. R. Green, J. A. B. Lohman, R. Kerssebaum, D. Kilgour and R. E. Mewis, J. Am. Chem. Soc., 2011, 133, 6134-6137.

12 E. B. Dücker, L. T. Kuhn, K. Münnemann and C. Griesinger, J. Magn. Reson., 2012, 214, 159-165.

13 A. N. Pravdivtsev and J.-B. Hövener, Chem. - Eur. J., 2019, 25, 7659-7668.

14 Z. J. Zhou, J. Yu, J. F. P. Colell, R. Laasner, A. Logan, D. A. Barskiy, R. V. Shchepin, E. Y. Chekmenev, V. Bum, W. S. Warren and T. Theis, J. Phys. Chem. Lett., 2017, 8, 3008-3014.

15 A. S. Kiryutin, A. V. Yurkovskaya, H. Zimmermann, H. M. Vieth and K. L. Ivanov, Magn. Reson. Chem., 2018, 56, 651-662.

16 A. N. Pravdivtsev, K. L. Ivanov, A. V. Yurkovskaya, P. A. Petrov, H. H. Limbach, R. Kaptein and H. M. Vieth, J. Magn. Reson., 2015, 261, 73-82.

17 P. J. Rayner, M. J. Burns, A. M. Olaru, P. Norcott, M. Fekete, G. G. R. Green, L. A. R. Highton, R. E. Mewis and S. B. Duckett, Proc. Natl. Acad. Sci. U. S. A., 2017, 114, E3188-E3194.
18 M. Fekete, O. Bayfield, S. B. Duckett, S. Hart, R. E. Mewis, N. Pridmore, P. J. Rayner and A. Whitwood, Inorg. Chem., 2013, 52, 13453-13461.

19 R. E. Mewis, Magn. Reson. Chem., 2015, 53, 789-800.

20 D. A. Barskiy, A. N. Pravdivtsev, K. L. Ivanov, K. V. Kovtunov and I. V. Koptyug, Phys. Chem. Chem. Phys., 2016, 18, 89-93.

21 T. Theis, G. X. Ortiz, A. W. Logan, K. E. Claytor, Y. Feng, W. P. Huhn, V. Blum, S. J. Malcolmson, E. Y. Chekmenev, Q. Wang and W. Warren, Sci. Adv., 2016, 2, e1501438.

22 S. S. Roy, K. M. Appleby, E. J. Fear and S. B. Duckett, J. Phys. Chem. Lett., 2018, 9, 1112-1117.

23 S. S. Roy, P. Norcott, P. J. Rayner, G. G. R. Green and S. B. Duckett, Chem. - Eur. J., 2017, 23, 10496-10500.

24 S. S. Roy, P. J. Rayner, P. Norcott, G. G. R. Green and S. B. Duckett, Phys. Chem. Chem. Phys., 2016, 18, 24905-24911.

25 S. S. Roy, P. Norcott, P. J. Rayner, G. G. Green and S. B. Duckett, Angew. Chem., Int. Ed., 2016, 55, 15642-15645.

26 J. N. Bae, Z. J. Zhou, T. Theis, W. S. Warren and Q. Wang, Sci. Adv., 2018, 4, 7.

27 D. A. Barskiy, S. Knecht, A. V. Yurkovskaya and K. L. Ivanov, Prog. Nucl. Magn. Reson. Spectrosc., 2019, 114-115, 33-70.

28 J. M. Brown, Chem. Soc. Rev., 1993, 22, 25-41.

29 D. B. Eremin and V. P. Ananikov, Coord. Chem. Rev., 2017, 346, 2-19.

30 S. Knecht, A. N. Pravdivtsev, J. B. Hovener, A. V. Yurkovskaya and K. L. Ivanov, RSC Adv., 2016, 6, 24470-24477.

31 A. N. Pravdivtsev, A. V. Yurkovskaya, H. M. Vieth, K. L. Ivanov and R. Kaptein, ChemPhysChem, 2013, 14, 3327-3331.

32 L. S. Lloyd, R. W. Adams, M. Bernstein, S. Coombes, S. B. Duckett, G. G. R. Green, R. J. Lewis, R. E. Mewis and C. J. Sleigh, J. Am. Chem. Soc., 2012, 134, 12904-12907.

33 M. Fekete, P. J. Rayner, G. G. R. Green and S. B. Duckett, Magn. Reson. Chem., 2017, 55, 944-957.

34 P. J. Rayner, P. Norcott, K. M. Appleby, W. Iali, R. O. John, S. J. Hart, A. C. Whitwood and S. B. Duckett, Nat. Chem., 2018, 9, 4251.

35 L. S. Lloyd, A. Asghar, M. J. Burns, A. Charlton, S. Coombes, M. J. Cowley, G. J. Dear, S. B. Duckett, G. R. Genov, G. G. R. Green, L. A. R. Highton, A. J. J. Hooper, M. Khan, I. G. Khazal, R. J. Lewis, R. E. Mewis, A. D. Roberts and A. J. Ruddlesden, Catal. Sci. Technol., 2014, 4, 3544-3554.

36 S. Knecht, S. Hadjiali, D. A. Barsiciy, A. Pines, G. Sauer, A. S. Kiryutin, K. L. Ivanov, A. V. Yurkoyskaya and G. Buntkowsky, J. Phys. Chem. C, 2019, 123, 16288-16293.

37 H. Kessler, S. Mronga and G. Gemmecker, Magn. Reson. Chem., 1991, 29, 527-557.

38 A. N. Pravdivtsev and J. B. Hovener, Chem. - Eur. J., 2019, 25, 7659-7668.

39 K. L. Ivanov, A. N. Pravdivtsev, A. V. Yurkovskaya, H. M. Vieth and R. Kaptein, Prog. Nucl. Magn. Reson. Spectrosc., 2014, 81, 1-36.

40 E. B. Ducker, L. T. Kuhn, K. Munnemann and C. Griesinger, J. Magn. Reson., 2012, 214, 159-165. 